
service in Ga-Rankuwa

\author{
Fatima Laher, MB BCh, Dip HIV Man (SA) \\ Perinatal HIV Research Unit, University of the Witwatersrand, Johannesburg \\ Claire Cullen, FCOphth, MMed \\ J Baile Matlala, FCOphth, MMed \\ Department of Ophthalmology, Dr George Mukhari Hospital, Ga-Rankuwa, Gauteng
}

Corresponding author: F Laher (laherf@phru.co.za).

Objective. There are few data from before the antiretroviral therapy (ART) era for cytomegalovirus retinitis (CMV-R) from settings where cost limits use of systemic treatment. This study examines CMV-R treatment and survival outcomes in a public hospital ophthalmology service in GaRankuwa, South Africa.

Methods. From October 2009 to October 2010, voluntarily consenting participants over the age of 15 years with incident clinically diagnosed CMV-R seen at the Dr George Mukhari Hospital ophthalmology clinic were prospectively enrolled in an observational study. Treatment was per clinic protocols and patients were followed up with structured data collection for up to 6 months.

Results. Eight individuals, all HIV infected and 50\% female, were identified and enrolled. At enrolment, median age was 38 years (interquartile range (IQR) 32 - 39 years), median CD4 count 20 cells/ $\mu \mathrm{l}$ (IQR 13 - 46.5 cells/ $\mu \mathrm{l}$ ), and $50 \%$ were currently receiving ART (mean duration of ART use 18 days, standard deviation (SD) 2.99 days). No participant received systemic ganciclovir, but 6 reported symptom combinations suggesting systemic CMV: shortness of breath $(n=3)$, diarrhoea $(n=3)$ and/or central nervous system complaints $(n=3)$. Ten eyes had visual impairment less than counting fingers at enrolment. Treatment combinations were: ART plus intravitreal ganciclovir $(n=5)$, intravitreal ganciclovir alone $(n=2)$, and ART alone $(n=1)$. Six-month outcomes were: death $(n=1)$, survival $(n=6)$, loss to follow-up $(n=3)$, untraceable $(n=1)$, systemic symptom resolution $(4 / 4)$, visual acuity deterioration (0/5), and persisting uveitis (2/3).

Conclusion. In the ART era, incident CMV-R appears to be uncommon in this setting. CMV-R may occur within the first 3 weeks after ART initiation. Even in CMV-R patients with suggestive systemic symptoms, 6-month survival is good despite no systemic CMV therapy.

S Afr J HIV Med 2012;13(2):68-71
South Africa has both a high burden of HIV disease ${ }^{1}$ and a large, expanding antiretroviral therapy (ART) programme. ${ }^{2}$ It is noteworthy that many South African HIV patients present for treatment when the CD4 count is less than 50 cells $/ \mu 1 .{ }^{3}$ Particularly in these individuals with advanced immune compromise, opportunistic infections such as cytomegalovirus (CMV) may present. The most commonly recognised manifestation of CMV is CMV retinitis (CMV-R), but pneumonitis, colitis, oesophagitis, adrenalitis, and neurological involvement are also described. ${ }^{4}$

In Africa, data describing the disease burden of CMV-R in the ART era are limited. In the pre-ART era, a 20-month longitudinal study in AIDS patients in Togo confirmed a 21.4\% incidence. ${ }^{5}$ Also in the pre-ART roll-out era in South Africa, 90 AIDS patients were treated for CMV-R at the University of Natal, and the incidence was noted to increase with time. ${ }^{6}$ A cross-sectional study screening all HIV patients with CD4 counts of $<50$ cells $/ \mu$ in Khayelitsha, South Africa, found 2\% of these patients to have CMV-R. ${ }^{5}$

CMV-R treatment strategies include localised and systemic therapies optimally used in combination and in initiation and maintenance phases, and the use of ART in the context of HIV diagnosis. CMV has been called the 'neglected disease of the AIDS pandemic', in part because of limited access to treatment, especially in the developing world, where localised intra-ocular ganciclovir implants and systemic oral valganciclovir are unavailable or too costly. Intravitreal ganciclovir injections, although more cost-effective, require highly skilled administration and may be inconvenient and/or unacceptable to patients.

ART combined with CMV treatment strategies is associated with an improvement in median survival after CMV-R diagnosis from 6 months to over 1 year., There are few ARTera data for CMV-R from African countries where cost limits the use of systemic CMV therapy.

This study describes the incidence of CMV-R in a public hospital outpatient ophthalmology clinic in Ga-Rankuwa, South Africa, over a 1-year period and examines treatment 
and survival outcomes of CMV-R cases over a 6-month follow-up period, so as to inform future CMV-R care.

\section{Methods Setting}

A prospective longitudinal observational study was conducted at the ophthalmology outpatient clinic of the Dr George Mukhari Hospital, a state tertiary academic service situated in Ga-Rankuwa, Gauteng province, South Africa. The hospital has a catchment population of 1800000 people from the surrounding Tshwane and Metsweding areas. In 2007, the antenatal HIV seroprevalence in Tshwane was $27 \%$ and in Metsweding it was $33 \% .^{10}$ At the time of the study, the hospital also offered an on-site HIV clinic with free ART access for HIV-infected adults with CD 4 counts less than 200 cells/ $\mu$ l or World Health Organization (WHO) stage 4 disease. ARV roll-out began in August 2004. In this setting, ophthalmology referrals are made by healthcare workers in the hospital and HIV clinic or in secondary and primary level facilities. Referral is based on presentation with any visual symptoms. In 2011, the HIV clinic saw 7853 patients of whom 193 initiated ART during that year.

\section{Eligibility}

Patients were eligible for entry into the study if they were aged 15 years or older; able to provide voluntary written informed consent (for those 18 years or older) or assent with parent/guardian consent (for those between 15 and 17 years old); and presented at Dr George Mukhari Hospital ophthalmology clinic with new clinically diagnosed CMV-R during the 1 -year enrolment period of the study.

\section{Case definition}

The CMV-R case definition was visualisation of at least one of the following on dilated pupil indirect ophthalmoscopy: indolent retinitis characterised by mild granular retinal opacification which may be associated with a few punctuate haemorrhages but absent vasculitis, or fulminating retinitis characterised by mild vitritis, vasculitis with perivascular sheathing and retinal opacification, dense, white, well-demarcated, geographical area of confluent opacification often associated with retinal haemorrhages, and slow relentless brushfire-like extension along retinal vascular arcades that may involve the optic nerve. ${ }^{11}$

\section{Data collection}

From 6 October 2009 to 6 October 2010, participants identified by clinic staff as having a possible CMV-R diagnosis from routine retinal screening (indirect ophthalmoscopy with fully dilated pupils) were referred to study representatives at the same clinic for assessment of eligibility, voluntary informed consent procedures and enrolment into the study.
Structured data collection by ophthalmologists was done at enrolment on the day of referral, and at months 3 and 6. This involved two components: (i) a clinical interview to record demographics, HIV status, CD4 count results, use of ART and CMV treatments, ocular symptoms, and a brief systemic symptom screen probing shortness of breath, diarrhoea, fever, headache, change in personality and decreased concentration; and (ii) visual acuity measurements using a Snellen chart or gross visual tests for vision worse than $6 / 120$, and an ophthalmological examination including indirect ophthalmoscopy with fully dilated pupils to categorise CMV-R zonal location and to assess the presence of CMV-R complications, namely vitreous haemorrhage, cataract, endophthalmitis and uveitis.

Treatment was neither influenced nor provided by the study, but was managed by the clinic according to local standard of care. Patients were referred to the HIV clinic for ART per South African guidelines. Management of CMV-R in this setting was predetermined by availability of ganciclovir only. Current accepted practice in the developing world is intravitreal ganciclovir injection twice a week for the first 2 weeks, and then weekly until the $\mathrm{CD} 4$ count recovers to over $150 \mathrm{cells} / \mu \mathrm{l}$ or retinitis becomes quiescent. However, intravitreal ganciclovir is not recommended for patients who will not have recoverable vision, who have

\section{Table 1. Summary of participant characteristics, treatment and symptoms at baseline and 6 months}

\begin{tabular}{|c|c|c|c|c|c|c|c|}
\hline \multirow[b]{2}{*}{ Participant } & \multicolumn{6}{|c|}{ Baseline characteristics } & \multirow[b]{2}{*}{$\begin{array}{l}\text { Six-month follow-up of } \\
\text { symptomatic outcomes }\end{array}$} \\
\hline & Gender & $\begin{array}{l}\text { Age } \\
\text { (years) }\end{array}$ & $\begin{array}{l}\text { Presenting ocular } \\
\text { symptoms }\end{array}$ & $\begin{array}{l}\text { Presenting systemic } \\
\text { symptoms }\end{array}$ & $\begin{array}{l}\text { CMV-R } \\
\text { treatment }\end{array}$ & $\begin{array}{l}\text { ART } \\
\text { use }\end{array}$ & \\
\hline 1 & $\mathrm{~F}$ & 27 & Decreased vision & $\begin{array}{l}\text { Shortness of breath, } \\
\text { diarrhoea, fever, } \\
\text { headache, personality } \\
\text { changes, decreased } \\
\text { concentration }\end{array}$ & No & Yes & $\begin{array}{l}\text { Ocular symptoms unresolved but } \\
\text { systemic symptoms resolved }\end{array}$ \\
\hline 2 & $\mathrm{~F}$ & 31 & Ocular dryness & Diarrhoea & $\begin{array}{l}\text { Intravitreal } \\
\text { ganciclovir }\end{array}$ & Yes & $\begin{array}{l}\text { Ocular and systemic symptoms } \\
\text { resolved }\end{array}$ \\
\hline 3 & M & 44 & $\begin{array}{l}\text { Ocular redness and } \\
\text { photophobia }\end{array}$ & Shortness of breath & $\begin{array}{l}\text { Intravitreal } \\
\text { ganciclovir }\end{array}$ & Yes & $\begin{array}{l}\text { Defaulted follow-up but } \\
\text { confirmed alive }\end{array}$ \\
\hline 4 & $\mathrm{~F}$ & 39 & Decreased vision & Nil & $\begin{array}{l}\text { Intravitreal } \\
\text { ganciclovir }\end{array}$ & Yes & Death \\
\hline 5 & $\mathrm{~F}$ & 31 & Ocular dryness & Diarrhoea & $\begin{array}{l}\text { Intravitreal } \\
\text { ganciclovir }\end{array}$ & Yes & $\begin{array}{l}\text { Ocular and systemic symptoms } \\
\text { resolved }\end{array}$ \\
\hline 6 & $\mathrm{M}$ & 39 & $\begin{array}{l}\text { Blind spots, visual } \\
\text { distortions }\end{array}$ & $\begin{array}{l}\text { Headaches, generalised } \\
\text { pain }\end{array}$ & $\begin{array}{l}\text { Intravitreal } \\
\text { ganciclovir }\end{array}$ & Yes & $\begin{array}{l}\text { Ocular and systemic symptoms } \\
\text { resolved }\end{array}$ \\
\hline 7 & $\mathrm{M}$ & 44 & Blind spots, 'floaters' & Nil & $\begin{array}{l}\text { Intravitreal } \\
\text { ganciclovir }\end{array}$ & No & $\begin{array}{l}\text { Defaulted follow-up and survival } \\
\text { not ascertained }\end{array}$ \\
\hline 8 & M & 37 & $\begin{array}{l}\text { Blind sports, } \\
\text { photophobia }\end{array}$ & $\begin{array}{l}\text { Shortness of breath, } \\
\text { decreased concentration }\end{array}$ & $\begin{array}{l}\text { Intravitreal } \\
\text { ganciclovir }\end{array}$ & No & $\begin{array}{l}\text { Defaulted follow-up but } \\
\text { confirmed alive }\end{array}$ \\
\hline
\end{tabular}


less than 3 clock hours of disease in retinal zone 3 and no fundal view, and who cannot come for regular injections. ${ }^{6}$

Telephonic tracing was undertaken for participants who did not attend follow-up appointments.

\section{Statistical analysis}

Descriptive statistics are reported. There were insufficient cases reported to analyse risk factors for outcomes.

\section{Ethical considerations}

Ethical approval was received from the Medunsa Research and Ethics Committee before initiating the study.

\section{Results Baseline characteristics}

Over the 1-year enrolment period, 8 individuals were eligible and all agreed to participate in the study (Table 1). All were HIV infected and 50\% were female. The median age at first appearance of CMV symptoms was 38 years (intraquartile rage (IQR) 32 - 39 years). At enrolment, the median CD4 count was 20 cells/ $/$ l (IQR 13 - 46.5 cells/ $\mu \mathrm{l}$ ) and $50 \%$ were currently receiving ART (mean duration of ART use prior to CMV presentation 18 days, standard deviation (SD) 3 days).

Presenting ocular symptoms were either one or a combination of: blind spots $(n=3)$, decreased vision $(n=2)$, dry eyes $(n=2)$, photophobia $(n=2)$, eye redness $(n=1)$, visual distortions $(n=1)$ and 'floaters' $(n=1)$.

Six participants $(75 \%)$ reported systemic symptoms: shortness of breath $(n=3)$, diarrhoea $(n=3)$ and/or central nervous system complaints of headaches, personality changes and/or decreased concentration $(n=3)$.

A summary of visual acuity is presented in Table 2. Ten eyes were classified as having visual impairment less than counting fingers at enrolment.

Indirect ophthalmoscopy at enrolment revealed bilateral retinal involvement in 7 participants (88\%). The most common retinal zone affected was zone 3 (10 eyes), then zone 2 (8 eyes) and zone 1 (6 eyes). Uveitis was found in 7 cases, and vitreous haemorrhage was present in 1 case (Figs 1 and 2).

\section{Treatment}

None of the participants received systemic therapy, although 6 complained of systemic symptoms. The combination of ART and

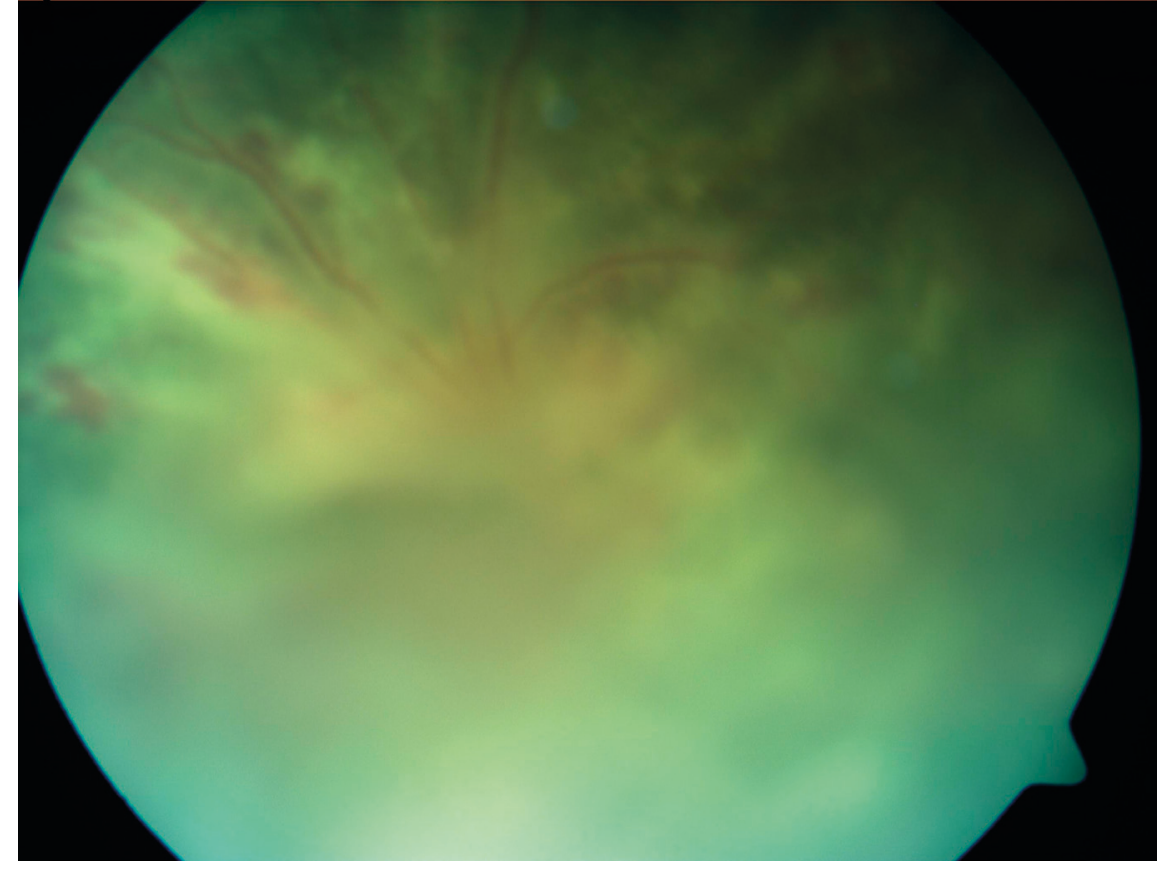

Fig. 1. Fundus photograph of the right eye of a 40-year-old woman with CMV-R. Vitreous haemorrhage, retinal detachment and retinitis are shown by the retinal opacification with associated retinal haemorrhages indicative of active CMV-R. The picture appears out of focus because the vitreous haemorrhage is anterior to the retina.

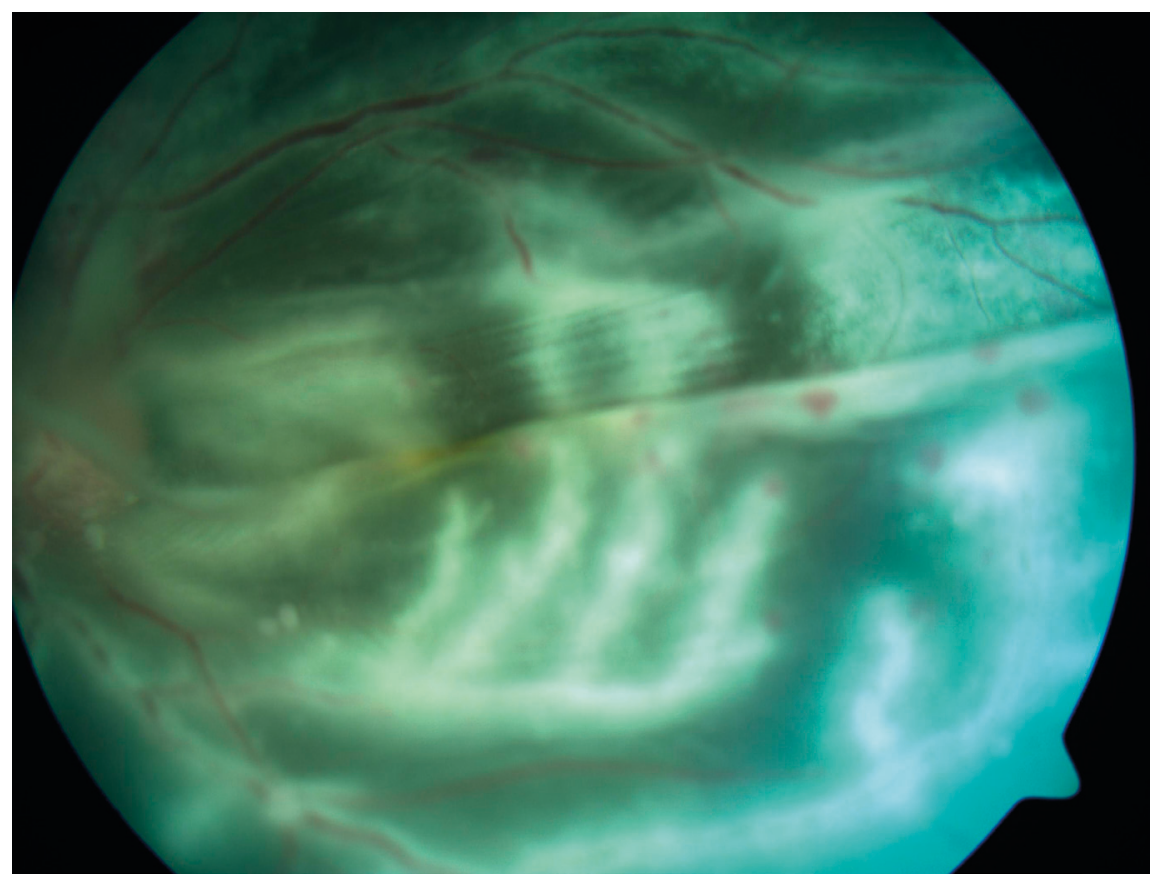

Fig. 2. Fundus photograph of the left eye of the same patient as in Fig. 1. Retinal detachment and retinitis are demonstrated by the retinal opacification and frosted branch angiitis, indicating active CMV-R disease.

intravitreal ganciclovir injections was given to 5 participants. Intravitreal ganciclovir alone was given to 2 male participants who both refused ART and defaulted from study followup. One patient, who had no light perception bilaterally, received only ART because visual benefit with intravitreal ganciclovir was not deemed likely.

\section{Six-month outcomes}

By month 6, 1 participant had died, 6 were alive and 1 was untraceable. Three participants had defaulted from follow-up.

Resolution of symptoms and complications at 6 months is described for the 4 participants who remained in follow-up. Ocular symptoms resolved for all 3 participants who received 
Table 2. Visual acuity at enrolment and month 6

\begin{tabular}{lllll}
\hline & \multicolumn{2}{c}{ Right eye $(N=8)$} & \multicolumn{2}{c}{ Left eye $(N=8)$} \\
\cline { 2 - 4 } Visual acuity category & Enrolment & Month 6 & Enrolment & Month 6 \\
\hline 6/6 - 6/12 vision & 0 & 0 & 4 & 2 \\
6/18- $6 / 60$ vision & 2 & 2 & 0 & 0 \\
Counting fingers to hand motions vision & 3 & 1 & 2 & 2 \\
Light perception to no light perception & 3 & 2 & 2 & 1 \\
Defaulted/died & Not applicable & 3 & Not applicable & 3
\end{tabular}

both intravitreal ganciclovir and ART, but did not resolve in the participant who received ART only. All 4 participants reported resolution of their systemic symptoms.

Visual acuity outcomes are presented in Table 2. Among the 5 participants who were followed up to month 6 , there was no recorded deterioration in visual acuity from enrolment; 6 eyes demonstrated no change and 4 eyes showed slight improvement.

Uveitis resolved in 2 of 3 cases, and in the third case where it persisted, a cataract developed. There were no cases of endophthalmitis.

\section{Discussion}

This study found a low incidence of CMV-R at a resource-constrained public hospital outpatient ophthalmology clinic in Ga-Rankuwa, South Africa: only 8 cases were identified in a 1-year period. The low incidence may be explained by the availability of ART in this population.

In this setting, CMV-R remains an AIDS manifestation, and the late presentation to care is highlighted not only by the low median CD 4 count of 20 cells $/ \mu$ l but also by the advanced stage of visual loss at enrolment.

Several studies from the pre-ART era describe improved or stable visual outcomes with intravitreal ganciclovir injections for CMV-R lesions. ${ }^{12,13}$ Importantly, even though none of the $75 \%$ of participants who reported systemic symptoms received systemic ganciclovir, the combination of ART and intravitreal ganciclovir did ameliorate visual symptoms in our study. However, possibly owing to severe visual loss, no patient had complete recovery of vision.

Currently the authors are unable to predict whether the 6-month outcomes reported here would have been better if state-of-the-art treatments such as ganciclovir implants and systemic valganciclovir had been available in our setting. A pressing question in the field of cytomegalovirus medicine is the relative efficacy of localised versus systemic treatment when CMV-R has been diagnosed, and until this is answered, management remains individualised. When comparing localised with systemic treatments, the latter carry an increased risk of systemic side-effects but also a reduced risk of systemic CMV dissemination.

There are several limitations to our study. First, the small sample size prevents statistical comparison of outcomes by treatment combination. Second, incidence may be underestimated because of missed diagnoses and lack of presentation to hospital. Third, when screening for systemic symptoms of CMV infection, no attempt was made to discriminate from co-morbidities. It has been noted, however, that systemic CMV symptoms have been misdiagnosed as Pneumocystis jirovecii pneumonia and tuberculosis, among others. ${ }^{14}$ Last, though we attempted in our mortality assessment to control for treatment defaulting by telephonic tracing, loss to follow-up may signify an underestimation of mortality, a phenomenon well described in studies of ART programmes. ${ }^{15}$

In conclusion, CMV-R is an uncommon disease in the ART era in Ga-Rankuwa, South Africa. Intravitreal ganciclovir, complemented with ART, was an effective option to treat CMV-R.

Acknowledgements. The authors wish to thank the hospital and the participants for their cooperation. This study was not funded. The authors declare that they have no conflicts of interest.

\section{References}

1. World Health Organization. AIDS Epidemic Update 2007. Geneva: UNAIDS World Health Organisation, 2007. http://data.unaids.org/pub/ epislides/2007/2007_epiupdate_en.pdf (accessed 20 December 2011)
2. National Department of Health, South Africa. HIV \& AIDS and STI Strategic Plan for South Africa 2007-2011. Pretoria: National Department of Health, 2007. http://www.info.gov.za/otherdocs/2007/ aidsplan2007/index.html (accessed 20 December 2011).

3. Coetzee D, Hildebrand K, Boulle A, et al. Outcomes after two years of providing antiretroviral treatment in Khayelitsha, South Africa. AIDS 2004;18:887-895. [PMID: 15322481]

4. Laher F, Ashford G, Cescon A, et al. Held to ransom - CNV treatment in South Africa. South African Journal of HIV Medicine 2010;11:31-34

5. Heiden D, Ford N, Wilson D, et al. Cytomegalovirus retinitis: the neglected disease of the AIDS pandemic. PloS Med 2007;4:1845-1851. [PMCID: 2100142]

6. Visser L. Managing CMV retinitis in the developing world. Comm Eye Health 2003;16:38-39. [PMID: 17491844]

7. Martin DF, Sierra-Madero J, Walmsley S, et al. A controlled trial of valganciclovir as induction therapy for cytomegalovirus retinitis. N Engl J Med 2002;346:1119-1126. [PMID: 11948271]

8. Holbrook JT, Jabs DA, Weinberg DV, et al. Visual loss in patients with cytomegalovirus retinitis and acquired immunodeficiency syndrome before widespread availability of highly active antiretroviral therapy. Arch Ophthalmol 2003;121:99-107. [PMID:12523893]

9. Gross JG, Bozzette SA, Mathews WC, et al. Longitudinal study of cytomegalovirus retinitis in acquired immune deficiency syndrome. Ophthalmology 1990;97:681-686. [PMID: 2160634]

10. National Department of Health, South Africa Report: The National HIV and Syphilis Prevalence Survey. Pretoria: National Department of Health, 2007. http://data.unaids.org/pub/ Report/2008/20080904_southafrica_anc_2008_ en.pdf (accessed 20 December 2011).

11. Kanski JJ. Clinical Ophthalmology. 6th ed. Philadelphia: Elsevier Health Sciences, 2007:477.

12. Henry K, Cantrill H, Fletcher C, Chinnock BJ, Balfour $\mathrm{HH}$ Jr. Use of intravitreal ganciclovir (dihydroxy propoxymethyl guanine) for cytomegalovirus retinitis in a patient with AIDS Am J Ophthalmol 1987;103:17-23. [PMID: 302618]

13. Ussery FM III, Gibson SR, Conklin RH, Piot DF, Stool EW, Conklin AJ. Intravitreal ganciclovir in the treatment of AIDS-associated cytomegalovirus retinitis. Ophthalmology 1988;95:640-648. [PMID: 2845321]

14. Martinson NA, Karstaedt A, Venter WD, et al. Causes of death in hospitalized adults with a premortem diagnosis of tuberculosis: an autopsy study. AIDS 2007;21:2043-2050. [PMID: 17885294]

15. Geng EH, Bangsberg DR, Musinguzi N. Understanding reasons for and outcomes of patients lost to follow-up in antiretroviral therapy programs in Africa through a sampling-based approach. J Acquir Immune Defic Syndr 2009;53:405-411. PMID: 19745753] 